\title{
Siamon Gordon on the challenges of retirement
}

S iamon Gordon (Figure 1) officially retired from his professorship at the University of Oxford, United Kingdom, at the end of 2008, after a long and successful career studying macrophage immunobiology. However, Gordon has not stopped work; he is currently in the midst of a post-retirement sabbatical (a "transitional year," as he referred to it) as a Visiting Scientist at the NIH. The JCI spoke with Gordon about his career, his year at the NIH, and his future plans.

JCI: What are you working on during your year at the NIH?

Gordon: I don't actually have a lab here at the NIH. I did bring one postdoc over with me, but she has moved on to take up a position in France. I also brought a number of strains of mice lacking specific nonopsonic receptors (phagocytic receptors), and I'm trying to get different people to use them in the disease models they study, so that we can investigate the role of the macrophage in these conditions. Much of my time is spent interacting with my two wonderful hosts here at the NIH, Alan Sher (whose lab works on parasite immunology) and Giorgio Trinchieri (whose lab works on the role of cytokines and inflammation in carcinogenesis and cancer progression, prevention, and destruction) and the people in their laboratories. There are over 2,000 immunologists at the NIH, and I keep finding new groups to interact with; I could spend a whole year talking to

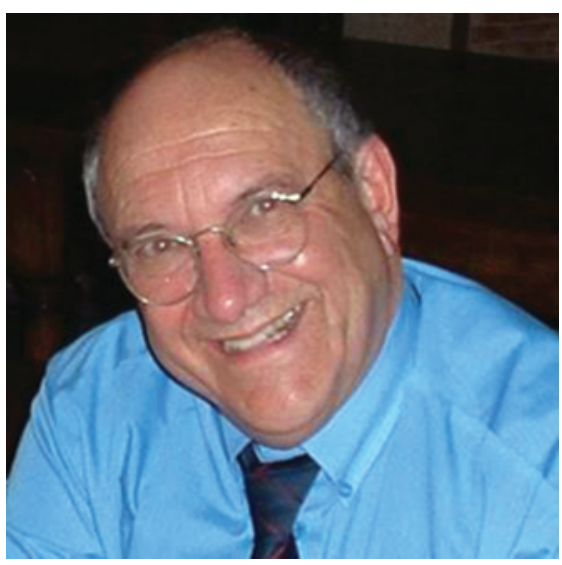

Figure 1

Siamon Gordon, Emeritus Professor of Cellular Pathology at the University of Oxford, retired at the end of 2008 . He is currently spending a transitional year as a Visiting Scientist at the $\mathrm{NIH}$. people! Other things that I'm focusing on include finishing up writing papers from the work that was done in my laboratory in Oxford; researching material for a book I'm hoping to write about the Nobel laureate Elie Metchnikoff, a pioneer in the field of cellular immunology who recognized the role of leukocyte recruitment and microbe phagocytosis in host defense; and trying to find more money for the AIDS prevention project in South Africa that I have been involved with for nearly a decade. As you can see, there is plenty to do, and I wouldn't mind being a bit more retired.

JCI: Do you miss the collegiate environment of Oxford now that you are at a much larger institution?

Gordon: Although the medical research community at the NIH is definitely bigger than at Oxford University, in my experience it is very collegiate, maybe even more so than Oxford was. Everyone has been extremely welcoming, friendly, and interactive. Most groups are relatively small, with fewer than 10 researchers, so they often depend on collaborations with other groups to get things done. I signed up for the immunology e-mail list when I arrived and I get at least 10 requests a day from people asking if anyone has a reagent, mouse, or machine that they can use. It might be a bit naive, and I might be getting a very rosy view of the place because I haven't encountered the bureaucracy, but I have found it to be like a huge family. They organize concerts in the eating areas and there are lots of social events; people can make a life here. I find it very intriguing.

JCI: Are you enjoying the chance to focus on work without the responsibilities of running a lab and being involved in departmental activities?

Gordon: I definitely appreciate the position that I am in, and I feel fantastically privileged to be here at the NIH not having to worry about finding money for the lab and making difficult decisions about which mice I can afford to keep; it does seem to be getting harder and harder for people. On the other side of the equation, I do miss having a lab. Here at the NIH, I depend on what they call "OPLs" (other people's labs), in that all my ideas need to be tested in other people's laboratories. I think that this is something that will eventually frustrate me, and that is why I'm trying to move toward projects that I can do myself, such as the book about Metchnikoff.

JCI: What are your plans for after your year at the NIH?

Gordon: My general plan is to go back to Oxford, where I am an Emeritus Professor of Cellular Pathology, and have that as my main base. Some plans are not yet concrete, but I am hoping to do a lot of traveling to research my book on Metchnikoff. For example, I want to travel to Odessa, Russia, where he performed much of his work, and the Pasteur Institute in Paris, France, where he ended his career.

JCI: You mentioned above the AIDS prevention project in South Africa that you are involved with, do you have more projects of this nature in the pipeline?

Gordon: My goal here is not to take on new projects but to improve on the one I have. Going back to 2000, when I initiated the project, HIV was such a huge problem in South Africa, my home country, that I wanted to do something to help. I didn't want to work on a vaccine or on antiretrovirals, rather I wanted to do something to promote prevention (social vaccination). I enlisted the help of Fran Balkwill, a professor at the Barts \& The London School of Medicine \& Dentistry, United Kingdom, who is a fantastic communicator of science, and Mic Rolph, a graphic designer, to write and illustrate an accessible but scientifically and medically accurate book about HIV that would teach young people in South Africa about the risks of infection and how to behave in ways to avoid it. The first book, Staying alive: fighting HIV/AIDS, was published in English in 2002 and distributed to schools in South Africa. This book worked well, at least for the white middle class, many of whom told me they finally understood how HIV was transmitted. I was always disappointed that a second edition didn't include the word "macrophage," but more importantly we learned from nongovernmental organizations (NGOs) and many children that the way some of our messages were taken was not quite the way we had thought we portrayed them. The result was that we modified the language and images so that they were more culturally compatible. With the support of the Bill \& Melinda Gates Foundation, we were able to publish a second English version of the book, You, me, and HIV (Figure 2), 


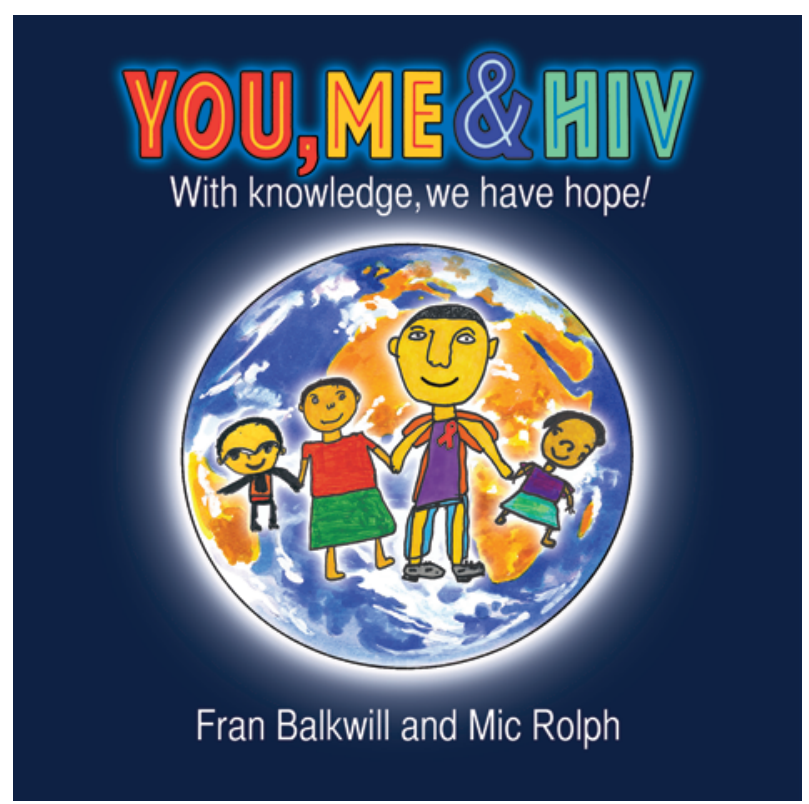

Figure 2

Siamon Gordon developed the idea for the book You, me, and HIV. Written by Fran Balkwill and illustrated by Mic Rolph, You, me, and HIV is designed to teach young people in South Africa the risks of infection with HIV and how to behave in ways that avoid it.

and translations in Zulu and Afrikaans. We tried to scale up our distribution of this to more schools throughout South Africa, but we found that we couldn't control distribution (you need to make sure not only that it reaches the schools, but that it gets from the head teacher's office to the teachers, and then to the children) and that at times the books ended up sitting in an office and did not reach our target audience, the children. My thoughts now are that we need to make this a small, focused project, and we are hoping to partner with the many NGOs that operate in South Africa. However, it will be a long haul before we achieve our goal, since behavioral messages are notoriously difficult to get across; it was a long time after the discovery that smoking causes lung cancer that it was banned in public places.

JCI: You spent your career working on macrophage immunobiology. What do you consider your greatest scientific accomplishment?

Gordon: The idea of the macrophage as a unique cellular system with different permutations in different parts of the body. We played roulette with antibodies seeking to define macrophage markers and identified F4/80. Using an antibody specific for F4/80, we were able to show that macrophages are found throughout the body, including a network of delicately arborized cells in the brain. Macrophages are homeostatic, trophic nurse cells as well as phagocytic killers.

JCI: Some immunologists consider the macrophage a poor relation to the DC. Do you see the fortunes of the macrophage changing in the future?

Gordon: I believe that DCs are specialized macrophages with unique properties - they present antigen to naive T cells. I like to use the words of the Greek philosopher Archilochus "The fox knows many things, the hedgehog knows one big thing" to explain it; I think of the macrophage as the fox, with many functions, and the DC as the hedgehog, which does one big thing, presenting antigen to naive $T$ cells.

As for the future, I'm not holding my breath that things will change, the macrophage is still on the sidelines of immunology, and you often go to an immunology meeting where there are no talks on macrophages. The cytokine and TLR fields of research, both of which came out of the study of macrophage biology, have given the macrophage some respectability, especially in innate immunity.

JCI: Having spent many years as a successful researcher, what advice do you have for those just beginning their careers?

Gordon: My honest advice is to stay close to the best possible lab that you can. Postpone early promotions and titles if they move you away from the best labs and best institutions; take your time to mature. Make sure you make time to think about what you do. My wife likes to say that I spend a lot of time "mulling over the macrophage." Try to find a field of research that is between disciplines - macrophages were never considered truly to fit into hematology or immunology - and try to study a less fashionable topic, it gives you time to think.

\section{Karen Honey}

